\title{
Educación escolar y masonería: krausismo y laicidad entre España y Costa Rica a finales del siglo XIX
}

\section{Scholar Education and Freemasonry: Krausism and Secularism between Spain and Costa Rica at the end of the 19th century}

\author{
Yván Pozuelo Andrés \\ Historiador y profesor de francés en el IES Universidad Laboral de Gijón, España. Editor de la REHMLAC+ y \\ de la Colección Historiadores de la Masonería de la editorial Masonica.es en España. Correo electrónico: \\ yvan@telecable.es
}

\author{
Ricardo Martínez Esquivel \\ Profesor de historia de la cultura, investigador y director de la REHMLAC+, en la Universidad de Costa Rica. \\ Correo electrónico: ricardo.martinezesquivel@ucr.ac.cr
}

DOI: http://dx.doi.org/10.15517/rehmlac.v9i1.28631

Fecha de recibido: 15 de noviembre de 2016 - Fecha de aceptación: 20 de enero de 2017

\section{Palabras clave}

Modernidad; nuevas ideas; sociedad civil; esfera pública; asociacionismo.

\author{
Keywords \\ Modernity; New Ideas; Civil Society; Public Sphere; Associationism.
}

\section{Resumen}

En el último tercio del siglo XIX, la educación en Costa Rica experimentó un lento proceso de crecimiento en el número de centros educativos, aumentó los índices de alfabetismo e intentó expandirse sin discriminación sexual y socioeconómica al obtener un carácter gratuito y obligatorio. El proyecto educativo estatal buscó la secularización y la formación de ciudadanos en un proceso de apropiación de ideales de la modernidad. Lo anterior, paralelo al desarrollo de centros de estudio, sociedades científico-literarias y patrióticas, el teatro y las campañas de higienización. Esta visión estatal fue coincidente con la visión masónica. A partir de un análisis prosopográfico se propone la siguiente hipótesis: La participación de educadores en la masonería costarricense partidarios de la institución libre de enseñanza, el krausismo, el positivismo y el racionalismo, se debió a que estos encontraron en la logia el principio de libertad de expresión con el que estaban identificados durante una época en que el liberalismo fue la vanguardia de la expansión de la esfera pública en el país. Muchos de estos educadores masones fueron españoles.

\begin{abstract}
From 1870 to 1900 , education in Costa Rica experienced a slow growth in the number of schools, increased literacy rates and tried to expand without gender and socioeconomic discrimination since school attendance was compulsory and free of charge. The state of Costa Rica's education project sought secularization and the education of its citizens within in a process of appropriation of the ideals of Modernity. This happened at the same time as the development of research centres, scientific, literary and patriotic societies, theatres and sanitation campaigns. This State's vision coincided with a Masonic vision. From a prosopographical analysis
\end{abstract}


we propose the following hypothesis: The participation of educators in Costa Rica's Freemasonry also belonged to the Institución Libre de Enseñanza, a secular educational institution based on Krausism, Positivism and Rationalism. Their belonging to both institutions was due to the lodge's principle of freedom of speech at a time when liberalism was at the forefront of the country's expansion of the public sphere. Many of these educators were Spanish freemasons.

"La logia española nos hace saber que escuela láica (sic) es sinónimo de escuela masónica"

La Unión Católica (6 de agosto de 1888, Madrid, España): 3.

\section{Introducción}

La masonería ha participado en los últimos 300 años en todos los grandes planteamientos de futuro que las generaciones en cuestión fueron ideando, proyectando y desarrollando. El caso de la educación escolar, es decir del lugar ocupado en la sociedad por la instrucción organizada, provocó, llegado el momento, numerosas reflexiones en el seno de la logia. Como con otros momentos relacionados con las masonerías y los masones, cabe matizar el verdadero papel jugado por estas y estos en la materia. Desde el último cuarto del siglo XX, la historiografía presentó sobre esta relación entre educación escolar y masonería, varios estudios aclaratorios, alejados de la visión halagadora masónica y de la terrorífica antimasonería de origen religioso.

En base a esa dinámica académica, queremos presentar en dos partes, un análisis introductorio de la relación educación escolar y masonería. La complejidad del tema y los múltiples factores humanos que interactuaron durante la época contemporánea sobre esta cuestión tan solo permiten, para cumplir con el espacio destinado a este trabajo, entreverlos y generalizarlos. ¿Qué pensaron las masonerías y los masones sobre la educación escolar? ¿Qué papel jugaron en los sistemas escolares? ¿Se puede hablar de educación (escolar) masónica? ¿Cuál fue esta praxis en el sistema educativo costarricense de los masones a finales del siglo XIX? Estas serían las preguntas a responder en la siguiente investigación.

La masonería se organizó en Costa Rica en 1865, experimentando por el resto del siglo un sube y baja en sus actividades debido a factores políticos, religiosos y masónicos ${ }^{1}$. También durante este último tercio se desarrolló el advenimiento de ideas krausistas, positivistas y racionalistas en relación con el sistema educativo en el país. Muchas de estas ideas fueron traídas por inmigrantes españoles ${ }^{2}$, algunos de los cuales se asociaron a la

\footnotetext{
${ }^{1}$ Véase sobre ello la investigación de Ricardo Martínez Esquivel, Masones y masonería en la Costa Rica de los albores de la Modernidad (1865-1899) (San José: EUCR, 2017).

${ }^{2}$ En particular consúltese el trabajo de Manuel Ledesma Reyes, "Krausismo y educación en Costa Rica: La influencia de los educadores canarios: Valerio y Juan Fernández Ferraz" (Tesis de Doctorado en Filosofía, Universidad de La Laguna, 1994).
} 
logia masónica ${ }^{3}$. Por lo tanto, primero se sintetizan los principales hitos históricos de la intervención -o su intento- masónica en el modelo de educación escolar de la sociedad española; para luego a partir de un análisis prosopográfico acercarse a la relación entre la educación escolar y la masonería en la Costa Rica decimonónica.

I.

Se eligió tratar la educación escolar con el objetivo de limitar nuestro análisis a la instrucción entendida como una forma colectiva de enseñar por parte de los poderes y sectores políticos o económicos, desde lo local a lo estatal, aprendizajes, conocimientos, habilidades y competencias bajo un marco común, dirigidos a una población o parte de ella mayoritariamente en una edad comprendida entre la niñez y la adolescencia.

De forma grosera, podemos delimitar la historia de la masonería por siglos, la del XVIII, la del XIX y la del XX. El asunto escolar aparece como preocupación masónica a partir del segundo tercio del siglo XIX, pasados los cien años de la constitución de la Gran Logia de Inglaterra en 1717. Es decir que la orden ya tenía historia, y hasta entonces el asunto educativo no había formado parte, salvo excepciones, de sus designios ni reflexiones. Fueron los cambios sociales, producidos por la revolución industrial y la lucha de clases, que se vinieron operando en la sociedad en general quienes hicieron aflorar las reflexiones, las ideas y los proyectos desde diferentes sectores políticos e intelectuales. En ese periodo de poco más de un siglo de historia, la Iglesia católica tomó partido y luchó contra una masonería representada como una competidora moral y temporal capaz de arrebatarle el poder ostentado. Los masones eran sus nuevos grandes herejes. Los peores, puesto que según ella, las logias reunían a los herejes históricos (judíos, musulmanes, protestantes...) junto a los nuevos (ateos, socialistas, comunistas, anarquistas, liberales...).

La equivocada y enconada valoración de lo que era la masonería y de lo que hacían los masones, le impidió a la institución eclesiástica observar que en el siglo XVIII miles de sacerdotes nutrían sus filas, que en las logias la Biblia ocupaba un lugar preeminente y sobre todo que la masonería se constituyó como una organización contraria al ateísmo, como tantas otras organizaciones de esa época y de la siguiente (martinistas, rosacruces, teósofos, entre otras), pero el dogma y el miedo a perder el protagonismo arraigado y tan bien defendido durante siglos prevalecieron en su exacerbada postura antimasónica.

La cuestión de la educación se constituyó crucial en esa lucha que se fue construyendo durante el siglo XIX debido al monopolio del clero católico, quienes la utilizaron como su principal instrumento de propaganda dogmática, entre la que se incorporó la instrucción antimasónica. El sistema educativo se convirtió en la clave de la

\footnotetext{
${ }^{3}$ Miguel Guzmán-Stein, "Masones españoles en Costa Rica: el Krausismo y la Institución Libre de Enseñanza en la formación y desarrollo de la Democracia Liberal Costarricense", en Masonería Española y América, coord. José Antonio Ferrer Benimeli (Zaragoza: CEHME, 1993), Tomo I, 449-470.
} 
lucha entre los partidarios del antiguo régimen, del status quo, y los que reivindicaron cambios orientados a obtener mayores libertades en lo económico, lo moral y lo cotidiano, estimando obsoletas, estos últimos, gran parte de las prohibiciones que regían la vida social, política, económica y espiritual de la sociedad.

Entre los autores que estudiaron el tema con mayor profundidad en España, se encuentran José Antonio Ferrer Benimeli, Pedro Álvarez Lázaro, Enrique M. Ureña, Pere Sánchez Ferré y el especialista en la relación educación y masonería José Ignacio Cruz Orozco. Asimismo, la cuestión se abordó desde diferentes comunicaciones en los simposios organizados por el Centro de Estudios Históricos de la Masonería Española ${ }^{4}$. A través de ellos se analizaron las influencias filosóficas que los masones españoles utilizaron para plantear un esfuerzo particular en esta materia. Lo más destacable está en haber comprobado que la preocupación educativa se había adecuado al devenir de la sociedad. Esta cuestión aparece con mayor o menor peso en todas las investigaciones regionales y locales que se llevaron a cabo sobre la historia de la masonería en todas las provincias españolas, lo que permite visualizar con bastante precisión la relación entre educación y masonería en España.

La educación escolar no se contempló en las Constituciones de Anderson. Esta preocupación se adentró en las logias a partir del segundo tercio del siglo XIX. De todos los países en los que destacó la lucha por una escuela fuera del control eclesiástico, Francia acaparó las miradas. No obstante, este país no fue el primero ni el único en el que se libró una batalla permanente entre la Iglesia católica y los laicos por el control y la organización de la educación escolar, aunque fue en aquel país donde se difundieron al resto del mundo las mayores informaciones sobre dicha batalla. ¿Quién no ha oído hablar de Jules Ferry ${ }^{5}$ ? ¿Quién no sabe que en 1905 los legisladores franceses votaron a favor de la ley que separa a las iglesias del Estado? Sin embargo, se conoce bastante menos que los masones belgas lograron crear ¡la Universidad Libre de Bruselas en 1834! Y sobre todo que consiguieron sostenerla en el tiempo.

La preocupación sobre la instrucción pública aumentó a medida que cambiaron las bases económicas de la sociedad, gracias a un cada vez mayor rol social de la burguesía en la organización estatal. Los niveles de desarrollo de la revolución industrial y descomposición del antiguo régimen determinaron los matices de esas posturas, influyendo en los expresados por las masonerías. Por ejemplo, en Francia, la revolución francesa de 1789 y su posterior desenlace, permitieron abordar la cuestión de la instrucción con profusas reflexiones y propuestas. En los primeros años de la gran revolución, Condorcet

\footnotetext{
${ }^{4}$ Ferrer Benimeli, Índices de actas de los Symposia Internacionales de Historia de la Masonería Española (Zaragoza: CEHME, 2009).

5 Jules Ferry (1832-1893) estaba comprometido con el objetivo de una escuela gratuita, obligatoria y laica, antes de ser iniciado masón en 1875.
} 
animaba el debate más allá de la inclusión laicista ${ }^{6}$. En cambio, en España, sin la dimensión revolucionaria de 1789 y con la lentitud del desarrollo de la revolución industrial, se planteó otro tipo de enseñanza desde una filosofía desconocida por la Iglesia católica: el krausismo.

En un contexto de movimientos trasatlánticos de redes migratorias, bienes e ideas modernas ligados con el desarrollo de las masonerías americanas ${ }^{7}$, esta corriente filosófica y pedagógica llegó a ciertos países latinoamericanos como veremos en el caso de Costa Rica. Krausismo y masonería, en España, se asociaron con total naturalidad, dentro de un cierto tiempo prudencial de análisis entre ambos promotores, y al margen de las primeras personalidades que difundieron la corriente filosófica. El krausismo se introdujo por Julián Sanz del Río y se dinamizó con Francisco Giner de los Ríos ${ }^{8}$. Karl Krause, padre de esta corriente, desarrolló sus teorías en los años posteriores a su expulsión de la masonería. No obstante, en su Ideal de la Humanidad para la vida eligió a la orden como la asociación idónea capaz de llevar a cabo los cambios necesarios para lograr un mundo mejor, pacífico e igualitario. Serían luego los alumnos de estos dos pedagogos españoles quienes librarían una batalla permanente para imponer esa concepción pedagógica a un régimen católico, apostólico y romano a través de las fallas que se irán abriendo en ese obsoleto régimen que tuvo que sobrevivir cediendo parcelas de libertades a partir de la revolución de 1868 y hasta la llegada de la II República en 1931.

Este sistema de vida se apoya entre otras consideraciones, sobre la educación como medio de "progreso", es decir de desarrollo de las libertades de las clases sociales aún sometidas a un control económico y político por un régimen oligárquico: progresar a falta de un desarrollo industrial de tipo inglés o francés a través de la educación basada en el krausismo, método filosófico-pedagógico escogido por parte de las clases sociales que reclamaban liberalismo. La meta era, según sus propios contextos, para todos estos territorios europeos la implantación y expansión de escuelas laicas.

Los masones españoles y franceses que se interesaron a la cuestión eran pedagogos antes de ser masones. La introducción del tema educativo en las masonerías se hizo con las iniciaciones de estos hombres que trasladaron sus proyectos dentro de la orden, que a su vez, los adoptaron como moralmente suyos e instrumentos de defensa y ataque contra la dominación clerical en la enseñanza. La preocupación por el sistema educativo fue en

\footnotetext{
${ }^{6}$ Condorcet, Écrits sur l'instruction publique (París: Edilig, 1989). Condorcet (1743-1794) no fue masón pese a ser y seguir siendo considerado como tal en los panfletos masónicos y antimasónicos.

${ }^{7}$ Dévrig Mollés, “Transferencias y luchas culturales transatlánticas desde Argentina (1860-1910)”, en 300 años: masonerías y masones, 1717-2017. Tomo I: Migraciones, eds. Martínez Esquivel, Yván Pozuelo Andrés y Rogelio Aragón (Ciudad de México: Palabra de Clío, 2017), 146-163.

${ }^{8}$ Julián Sanz del Rio (1814-1869) y Francisco Giner de los Ríos (1839-1915) no fueron masones. Es más, este último "descalificaba sin rodeos a la masonería española de la época, ninguneaba la relación de ésta con los krausistas españoles de entonces y recriminaba el comportamiento que había tenido la masonería alemán con Krause”, según estudió Pedro Álvarez Lázaro, Páginas de historia masónica (Madrid: IDEA, 2006), 151.
} 
creciendo entre los masones españoles. Tras el parón vivido en las actividades masónicas españolas a finales del siglo XIX y luego de la pérdida de las colonias de ultramar, el tema educativo se convirtió en uno de los más abordados por los masones españoles. La estabilidad organizativa alcanzada en el siglo XX permitió asentar la cuestión a nivel nacional y sobre todo intentar pasar de la teoría a la práctica de forma independiente.

Esa preocupación por la cuestión educativa también se puede comprobar a través de los nombres simbólicos y de las logias que adoptaron títulos de pedagogos españoles y extranjeros. Lo dejamos simplemente apuntado por no disponer de espacio suficiente para analizar esta interesante y reveladora realidad de la atmósfera moral y política que se desprende de esa elección identificativa.

Sus proyectos de escuelas no iban dirigidos a los hijos de sus afiliados sino con el objeto de transformarlos como sistema nacional de enseñanza para todos los niños y niñas, y sobre todo, para los que procedían de clases bajas sin recursos.

La escuela laica, la escuela moderna, la escuela neutra, la escuela racionalista, es decir cualquier tipo de escuela que no estuviera controlada por la Iglesia católica, formó parte, groso modo, de las propuestas educativas masónicas. Esta forma de enseñanza se planteó desde los círculos liberales, librepensadores, y también por parte de los espacios culturales del movimiento obrero, en las casas del pueblo, ateneos obreros, o socialmente mixtos como el ateneo-casino, tantas formas de sociabilidades que integraron un programa educativo, con creaciones de bibliotecas, charlas, dentro de las amplias funciones culturales, educativas y políticas promovidas.

Por lo tanto, los masones se insertaron en una importante red social que proponía transformar el estado de la instrucción pública. Dentro de la práctica interna de logia, la beneficencia ocupó un lugar destacado, utilizado para apoyar a obras sociales olvidadas de las ayudas estatales. En este caso, no era un olvido sino una política muy pensada desde el poder oligárquico hacia esas escuelas vista como la preparación de hombres, sobre todo, y mujeres con el supuesto objetivo de destruir la moral católica, la institución eclesiástica, por consiguiente el régimen monárquico. Fantasía llevada al terror que los estudios universitarios desmintieron con exhaustividad y rotundidad. En efecto, los masones españoles tenían menos capacidad de actuación que la que hicieron creer y creía la Iglesia católica.

Una vez asentada la teoría laica en las masonerías faltaba pasar a la práctica. ¿Qué hacer si no se lograba por las vías legislativas imponer la creación de escuelas neutras subvencionadas por el erario público? ¿Por qué no crear y sostener una escuela laica ellos mismos? Tanto en el siglo XIX como en el XX, se conservó amplia documentación donde se anunciaba la creación de dichas escuelas, pero muy pocas se lograron construir y sostener. Sin embargo, estas iniciativas se consideraron por parte de los elementos ultramontanos como una muy seria amenaza moral y política. Según los diferentes estudios producidos sobre la historia de la masonería en cada región española, se concluye que solo 
una pequeña parte de todas las escuelas laicas se proyectaron y financiaron por los masones. En muchas de ellas, tan solo formaron parte de una red de apoyo junto a partidos políticos, sindicatos, círculos culturales, ayuntamientos e individuos. Incluso cuando llegó a funcionar durante unos años, congregó a un número reducido de alumnos.

Muchos proyectos, muchas polémicas dialécticas conservadas en la prensa de la época con los adversarios del laicismo pero poca efectividad. Era lo que se podía hacer en aquella época. Los boletines oficiales de las masonerías españolas y las actas de sus asambleas nacionales son la fuente primordial donde se puede seguir los avatares entre la proclama a favor de la creación de escuelas laicas y su práctica real. El primer intento por parte de las logias en crear una escuela laica data de 1872, en Barcelona. En esa misma ciudad, en 1880, se llevaría a cabo la primera experiencia real con la creación de la Sociedad Catalana de Amigos de la Enseñanza Laica. Luego, vendrían escuelas en Murcia, Albacete, Madrid, Zaragoza, Jaén, etcétera ${ }^{9}$. Las escuelas que sobrevivieron varios años no contaban con más de un centenar de alumnos. Así pues, los masones participaron dentro de un amplio movimiento a favor de la creación de escuelas neutras. Escasos fueron los proyectos donde sus promotores eran masones, situación dada por un contexto local particular. Dependía mucho de si las fuerzas políticas, culturales e intelectuales de una localidad se encontraban mayoritariamente o al menos cualitativamente en las logias. A modo de ilustración, destacó la logia Abd-el-Aziz de Tánger (Marruecos bajo el protectorado español) que promocionó la creación de varias escuelas laicas y gratuitas ${ }^{10}$. Esta obra la tomó a nivel nacional la masonería como el ejemplo a seguir en todo el país, animando a los masones españoles durante años a apoyar esta iniciativa en Tánger.

Así pues, los masones y las masonerías participaron del movimiento laicista español, empreñado de krausismo, y el cual ha tenido en la financiación privada su principal obstáculo. A pesar de no haber podido crear ni sostener la cantidad de escuelas proyectadas, permitieron seguir luchando con la dialéctica hacia una sociedad laica animada por la separación de las iglesias y el Estado logrado en el país galo en 1905. No tener el poder político dificultó grandemente aplicar cualquier proyecto contrario al pensamiento de la clase dominante. ¿Qué ocurrió cuando estos hombres, partidarios del laicismo, que no tenían el "poder" lo lograron?

De todos los regímenes españoles, el de la II República (1931-1939) puede ser considerado como el más cercano a los ideales laicos desde la perspectiva del poder. Entre el programa republicano, conjunción de partidos republicanos y el socialista, estaba el laicismo en la escuela. Es entonces donde la teoría tuvo un impulso y un apoyo, no exentos

\footnotetext{
${ }^{9}$ Ferrer Benimeli, "La escuela laica. Lugar de enfrentamiento entre la masonería y la Iglesia en España (18681930)", en École et Église en Espagne et en Amérique Latine-Aspects idéologiques et institutionnels, eds. Jean-René Aymes, Eve-Marie Fell y Jean-Louis Guerena (Tours : Université de Tours, 1988), 195-222.

${ }^{10}$ Ferrer Benimeli, "Preocupación de la masonería de Tánger por la educación y la paz en Marruecos (19051920)", Cuadernos de historia contemporánea 14 (1992): 75-89.
} 
de dificultades, para pasar a la práctica estatal. Así entonces, se crearon escuelas y sobre todo se desligó al clero de la escuela nacional, integrando a civiles como maestros y maestras y un programa educativo basado en la "ciencia" en contraposición al oscurantismo que se suponía enseñaban los religiosos, antiguos formadores de una inmensa mayoría de los laicistas del país. El bienio negro (1933-1936) puso al mando de la República a unos de sus adversarios, retrocediendo el nivel laicista recientemente iniciado. Por su lado, el golpe de Estado de julio de 1936 aniquiló al laicismo incipiente tras la victoria del Frente Popular en las urnas de febrero de aquel año.

Ninguno de todos los presidentes del gobierno republicano que perteneció a la masonería nombró a un masón como ministro de Instrucción Pública. En las votaciones sobre leyes que afectaron la educación nacional, los diputados masones no votaron al unísono sino que cada cual siguió, salvo excepciones, las consignas del partido al que pertenecía $^{11}$.

Uno de los ejemplos de escuela neutra cuya historia condensa las principales características expuestas lo constituyó la escuela neutra de Gijón, en Asturias ${ }^{12}$. Esta se organizó en 1911, unas semanas antes de la logia en dicha ciudad. Su creación es el fruto de meses de empeño por parte de los sectores liberales, anarcosindicalistas, socialistas, diversas entidades culturales, el ayuntamiento e individuos. Con los años, el ayuntamiento dejó de financiar la entidad educativa y los principales valedores con el tiempo se asociaron a la logia Jovellanos de Gijón. A la vez que se construyó el templo masónico de la ciudad, los masones pensaron en ubicarla en ese mismo edificio. El director de la escuela, Eleuterio Quintanilla, un teórico del anarcosindicalismo, masón e interlocutor respetado entre los diferentes círculos de la ciudad, se caracterizó por reclamar diferentes cambios en la sociedad. Lo más destacable de esta escuela fue su longevidad: 26 años. Es decir, echó raíces pedagógicas en la localidad, aunque tan solo un escaso número de niños y niñas se pudo aprovechar del proyecto. El golpe de Estado de 1936 y la conquista de la región asturiana en octubre de 1937 por parte de las tropas franquistas guillotinaron la entidad escolar. Retrocediendo entonces al exclusivo y férreo control educativo de los clérigos.

Observemos ahora la situación de la relación de la educación escolar y la masonería en Costa Rica a partir de las experiencias españolas expuestas hasta aquí.

\footnotetext{
11 José Ignacio Cruz Orozco, Masonería y Educación en la II República española (Alicante: Instituto de Cultura "Juan Gil-Albert", 1993), 122-123. El caso de Azaña es atípico puesto que tras celebrar su iniciación no regresó a ninguna reunión de logia.

12 Yván Pozuelo Andrés, La masonería en Asturias (1931-1939) (Oviedo: Universidad de Oviedo, 2012), $32-$ 35 .
} 
II.

La educación en Costa Rica para el momento de la Independencia (1821), tuvo una orientación católica; sin embargo, en el discurso de las élites políticas e intelectuales, como en el resto de las colonias españolas, los conceptos ilustrados de progreso, felicidad y civilización matizaron una preocupación por reformar el sistema educativo estatal ${ }^{13}$. Desde la Constitución de Cádiz, la educación se consolidó como una actividad municipal y se apropió del método lancasteriano como su paradigma enseñanza.

Durante el último tercio del siglo XIX se distingue que en el país terminó de plasmarse en algunos sentidos, un proyecto de sociedad civil promocionado desde la independencia y en el que participó un grupo particular de individuos desde la década de 1840, momento en que empezó a adquirir importancia la secularización social en el país ${ }^{14}$. Dicho proyecto tuvo un apartado sobre cómo debía ser el aparato educativo del Estado costarricense. Pronto se verá promovido este proyecto por una red de intelectuales y políticos fuertemente influenciados por los ideales de la ilustración y la modernidad.

En estos años, la educación experimentó un lento proceso de crecimiento en el número de escuelas y colegios, creó tardíamente la primera universidad, aumentó los índices de alfabetismo e intentó expandirse sin discriminación sexual y socioeconómica al obtener un carácter gratuito y obligatorio ${ }^{15}$. El proyecto educativo estatal buscó la secularización y la formación de ciudadanos, según el momento, a partir de los ideales del positivismo y el krausismo ${ }^{16}$. Este proyecto intentó inculcarle a las culturas populares valores burgueses e ilustrados como el patriotismo, el nacionalismo, la higiene, la disciplina laboral y la ciencia, así como la adscripción a los ideales del progreso en su sentido capitalista y positivista. Lo anterior, paralelo al desarrollo de centros de estudio, sociedades científico-literarias y patrióticas, el teatro y las campañas de higienización ${ }^{17}$.

Esta visión estatal coincidió con la visión masónica. Por ejemplo, en los Estatutos Civiles de la Masonería de Centro América se indicó como deber de la logia: "procurar la ilustración de sus miembros, fomentar la educación y propender al alivio de las clases

\footnotetext{
13 François-Xavier Guerra, Modernidad e independencias. Ensayos sobre las revoluciones hispánicas (Madrid: Editorial MAPFRE, 1992), 275-295. Juan Rafael Quesada Camacho, Educación y ciudadanía en Costa Rica de 1810 a 1821: del crepúsculo colonial al umbral de la modernidad política (San José: EUCR, 2007), 33-45.

${ }^{14}$ Véanse sobre esto, por ejemplo, los trabajos compilados en Iván Molina Jiménez y Steven Palmer, Héroes al Gusto y Libros de Moda. Sociedad y cambio cultural en Costa Rica (1750-1900) (San José: Editorial Porvenir, Plumsock Mesoamerican Studies, 1992).

${ }^{15}$ Ileana Muñoz García, Educación y régimen municipal en Costa Rica 1821-1882 (San José: EUCR, 2002), 73-89.

${ }^{16}$ María de los Ángeles Palacios Robles, "La formación del ciudadano costarricense de 1821-1886", Cuadernos para la Ciudadanía 3 (San José: EUCR, 2005).

${ }^{17}$ Gerardo Morales García, Cultura oligárquica y nueva intelectualidad en Costa Rica: 1880-1914 (Heredia: EUNA, 1995), 36-80.
} 
desvalidas" "18; también en el artículo 52 de dichos estatutos, se definió la masonería como una asociación de instrucción, ilustración y perfeccionamiento moral. De esta forma, se observa cómo los ideales manejados por el Estado-nación decimonónico en proceso de construcción fueron totalmente congruentes con los de la masonería; esto se explica en que tanto el uno como el otro provenían indudablemente de las mismas ideologías. Debido a esto, la masonería se convirtió en un espacio ideal para que muchos actores de la época se reunieran y expresaran su ideal de sociedad civil costarricense.

El medio fundamental de la masonería para transmitir sus ideas y valores entre sus miembros ha sido la educación. Por consiguiente, la presencia de los mismos ideales en el proyecto educativo estatal y en el discurso masónico, pudo llevar a algunos educadores a identificar el sistema de valores masónico con dicho proyecto, como bien sucedió en otras latitudes ${ }^{19}$.

Por lo tanto, en la masonería costarricense decimonónica, ¿qué significó la profesión educativa?, ¿cuantitativamente importó la participación de educadores en la logia o de masones en el aparato educativo?, ¿o será más bien que los aportes de los educadores masones fueron más cualitativos que cuantitativos y apoyando el desarrollo de la educación desde instancias distintas a la labor docente?

En primer lugar, buscando responder a las interrogantes anteriores se ha realizado un análisis prosopográfico a los 649 miembros de la masonería en Costa Rica entre los años 1865 y $1899^{20}$. De ellos, el $9 \%$ se dedicó a las actividades educativas (58 de 649 masones). Hubo dos maestros de escuela, 40 educadores de institutos secundarios y 16 profesores de la Universidad de Santo Tomás (única del país). Debido a estos datos, se ha analizado la participación de los educadores masones desde instancias distintas a la labor docente, como el Ministerio de Instrucción Pública, la Rectoría de la Universidad de Santo Tomás o la dirección de centros educativos.

Para la década de 1860 y hasta mediados de la siguiente década (1870), debido a la inestabilidad de las municipalidades, el modelo educativo municipal-religioso cayó en un

\footnotetext{
${ }^{18}$ Capítulo 4: "Deberes y Derechos colectivos", artículo 21, inciso 2-A. Archivo de la Gran Logia de Costa Rica (AGLCR), Estatutos civiles de la Masonería de Centro América (San José, 1884). El presidente y masón Bernardo Soto Alfaro como "Gran Protector del Orden Masónica", aprobó en nombre de la República de Costa Rica estos estatutos. Archivo Nacional de Costa Rica (ANCR), Series de Gobernación, Libro 1234, Folio 77.

${ }^{19}$ Puede revisarse para el caso del imperio británico a finales del siglo XIX, el trabajo de Paul John Rich, Elixir of Empire: The English Public Schools, Ritualism, Freemasonry, and Imperialism (Londres: Regency Press Ltd., 1989); mientras, que para el caso españa durante la II República, el de María Dolores Gómez Molleda, "Educación, masonería y Segunda República. Algunos aspectos críticos", Historia de la Educación 27 (2008): 131-152.

${ }^{20}$ Fuentes utilizadas: AGLCR, Ficheros de expedientes antiguos (1865-1899); Luis Felipe González Flores, Evolución de la instrucción pública en Costa Rica (San José: ECR, 1978), 293-318 y 424-430; González Flores, Historia de la influencia extranjera en el desenvolvimiento educacional y científico de Costa Rica (San José: ECR, 1976); Paulino González Villalobos, La Universidad de Santo Tomás (San José: EUCR, 1989), 161-164; y Guzmán-Stein, "Masones españoles en Costa Rica”, 449-470.
} 
estancamiento. Sin embargo, en dicha década, gracias a un aumento en el aporte económico del Ejecutivo y a la expansión de municipalidades debido a la creación de nuevos cantones, inició un nuevo proceso de crecimiento del aparato educativo, se extendió la alfabetización de los niños en las zonas rurales, se equiparó el sistema escolar en términos de género y se crearon nuevos centros de educación secundaria ${ }^{21}$.

En este contexto, determinados cambios en la educación fueron parte de las propuestas de un círculo de políticos e intelectuales liberales, algunos masones, que desde el año 1867 venían proponiendo una serie de reformas modernizantes del aparato educativo $^{22}$. En esta línea, las investigaciones de Miguel Guzmán-Stein han comprobado que extranjeros ${ }^{23}$, principalmente españoles, cubanos y puertorriqueños, fueron traídos por el Estado para dirigir centros de enseñanza de educación secundaria durante el último tercio del siglo XIX. Estos extranjeros introdujeron el krausismo y encontraron en la sociabilidad masónica una forma de insertarse socialmente en el país. No obstante, los educadores extranjeros traídos por el Estado y asociados a la masonería costarricense no solamente fueron los krausistas estudiados por Guzmán-Stein.

De los institutos secundarios más importantes de la Costa Rica de la época, solamente el Liceo de Costa Rica y el Colegio Superior de Señoritas no fueron dirigidas por masones en algún momento del siglo XIX. Distinto sucedió con la Escuela Central de San José, la Escuela Normal de San José, el San Luis Gonzaga de Cartago, el Instituto Nacional de San José, el Colegio de San José y el Instituto Universitario de San José, dirigidos en su momento por un extranjero asociado a la masonería costarricense. Por ejemplo, el nicaragüense Máximo Jerez (director de la Escuela Central de San José en 1866), abogado graduado de la Universidad de León, Nicaragua, importante liberal en su país y precursor del positivismo en Costa Rica ${ }^{24}$; o Valeriano Fernández Ferraz, miembro de la llamada generación de intelectuales krausistas españoles de la Universidad Central de Madrid, España, que incluyó entre otros a Emilio Castelar, Moret, Prieto y Caulier, todos discípulos de Sanz del Rio; y la mayoría miembros de la masonería española ${ }^{25}$.

\footnotetext{
${ }^{21}$ Muñoz García, Educación y Régimen Municipal, 73-89.

${ }^{22}$ Molina Jiménez, "Educación y sociedad en Costa Rica: de 1821 al presente (una historia no autorizada)", Diálogos Revista Electrónica de Historia 8, no. 2 (agosto 2007-febrero 2008 [citado el 15 de septiembre de 2015]): disponible en http://revistas.ucr.ac.cr/index.php/dialogos/article/view/18349/18539

23 Guzmán-Stein, "Masones españoles en Costa Rica”, 449-470; Guzmán-Stein, "Masones y liberales, españoles y cubanos: Intervención y aporte al desarrollo social, político y cultural de Costa Rica en el siglo XIX", en La Masonería Española entre Europa y América, coord. Ferrer Benimeli (Zaragoza: CEHME, 1995), Tomo I, 41-50; y Guzmán-Stein, "Costa Rica, España y Cuba: Antecedentes, desarrollo e impacto del movimiento de independencia en la sociedad costarricense finisecular y la masonería", en La Masonería Española y la crisis colonial del 98, coord. Ferrer Benimeli (Zaragoza: CEHME, 1999), Tomo II, 1041-1087.

${ }^{24}$ González Flores, Historia de la influencia extranjera, 55-65. El positivismo llegó al país con Jerez, antes de la llegada del insigne pedagogo cubano y de paso masón, Antonio Zambrana, quien no participó de la masonería costarricense.

${ }^{25}$ Krause se inició masón y en su imaginario, vio en la orden la génesis de la felicidad de las sociedades humanas. Enrique M. Ureña, "Masonería y pensamiento: Krause", en La masonería en la España del siglo
} 
Para seguir con los ejemplos, Juan Fernández Ferraz, en todo sentido siguió los pasos de su hermano mayor, Valeriano. Los hermanos Fernández Ferraz no solo introdujeron el krausismo en el país, sino que también las filosofías de la institución libre de enseñanza, las cuales estuvieron fundamentadas en el humanismo como medio formativo o educativo y se opusieron diametralmente a los principios positivistas. Por ende, ellos identificaron en estas filosofías educativas, principios similares a los del sistema de valores masónico, ya que sus orígenes están en la ilustración y la modernidad. Inclusive, mientras Valeriano dirigió el Colegio San Luis Gonzaga de la ciudad de Cartago durante el periodo 1871-1873, él, junto a sus hermanos Juan y Víctor, organizó la logia Progreso (1873-1874) en la misma ciudad. En esta logia se asociaron además de los hermanos Fernández Ferraz, dos profesores más de dicho instituto secundario ${ }^{26}$.

De igual manera, se ha identificado una situación interesante cuando Juan Fernández Ferraz fue el director del Instituto Universitario de la ciudad de San José (18841887), ya que de los doce educadores titulares, once fueron masones en algún momento de sus vidas ${ }^{27}$. La mayoría de estos educadores coincidieron en el San Luis Gonzaga, así como en Progreso u otras logias del país. Ante este tipo de situaciones cabe la hipótesis de que estos masones pudieron aprovechar lazos de camarería y amistad, o simplemente relaciones previas (capital social) para satisfacer un interés personal como lo pudo ser el laborar (obtener un empleo) en un instituto secundario o formar parte de un proyecto educativo con determinada filosofía.

El desenvolvimiento del Colegio San Luis Gonzaga y el Instituto Universitario, bajo los principios del krausismo y de la institución libre de enseñanza ${ }^{28}$, así como el desarrollo de la Universidad de Santo Tomás durante esta época, intensificaron los esfuerzos por secularizar la educación, en especial gracias al trabajo de los educadores extranjeros, de los cuales, como se ha visto, hubo masones. No obstante, este proceso incrementó la creciente diferenciación cultural entre los miembros de las redes políticas e intelectuales del país y el resto de la población, a pesar de que estos últimos, gracias al avance de la alfabetización,

XIX, coord. Ferrer Benimeli (Madrid: Junta de Castilla y León, Consejería de Educación y Cultura, 1987), Tomo II, 589-606. Ledesma Reyes, "Krausismo y educación en Costa Rica", 92-94.

${ }^{26}$ Cuando los hermanos Fernández Ferraz dejaron el Colegio San Luis Gonzaga, este les fue encargado a los jesuitas, terminando así con el krausismo y la institución libre de enseñanza en la educación secundaria cartaginesa, y de paso, con la masonería en dicha ciudad. Guzmán-Stein, "Masones españoles en Costa Rica", 449-470. Ledezma Reyes, "Krausismo y educación en Costa Rica", 193-298.

${ }^{27}$ AGLCR, "Registro de firmas Respetables Logias Unión Fraternal 19 (1883-1887); Regeneración 6 (18881899). Rafael Obregón Loría y George Bowden, La Masonería en Costa Rica. Tomo II (San José: Trejos Hermanos, 1938), 19-24. González Flores, Evolución de la instrucción pública en Costa Rica, 424-430.

${ }^{28}$ Vale señalar que al igual que el krausismo, el desarrollo de la institución libre de enseñanza ha tenido un fuerte vínculo con la masonería. Rafael Asín Vergara, "Relaciones e influencias entre la masonería y la Institución Libre de Enseñanza", en La masonería en la España del siglo XX, coord. Ferrer Benimeli (Zaragoza: CEHME, 1996), Tomo I, 373-404. Por su lado, el historiador Pedro Álvarez Lázaro concluyó que "no intervino, ni directamente ni indirectamente, en la fundación o en el mantenimiento de la ILE". En Páginas de historia masónica, 153. 
no quedaron marginados de la expansiva esfera pública costarricense-vallecentrista que empezó a configurarse desde la década de $1870^{29}$, o de la ampliación de la condición de ciudadano elector de segundo grado, que jugó un importante papel en la democratización política $^{30}$.

Por último y en tercer lugar, se analizan los cargos ostentados por masones de ministro de Instrucción Pública y de rector de la Universidad de Santo Tomás, entre los años 1865 y 1888, vida de esta institución de educación superior. De los nueve ministros y ocho rectores durante este periodo, por lo general, siempre hubo un masón como ministro o rector, con excepción del año 1887. Por otra parte, hubo masones como los abogados José María Castro Madriz y Lorenzo Montúfar, quienes fueron tanto ministros como rectores, e incluso, el primero ocupó ambos cargos al mismo tiempo durante unos años sin actividades masónicas en el país (1877-1879) ${ }^{31}$.

A partir del análisis prosopográfico efectuado a los masones, es posible determinar que no todos participaron en proyectos educativos, debido a que no todos fueron educadores o tuvieron nexos que les permitieron influir en este campo. Los masones que se vincularon a la educación y no fueron educadores, lo hicieron desde puestos altamente influyentes, lo cual les permitió tener un papel decisivo y además, les brindó, de paso, un prestigio social que como miembros de la élite probablemente estaban buscando.

No se debe olvidar que los principios de la masonería costarricense de estos años, eran en todo coincidentes con los del liberalismo (que pugnaba por un Estado laico y una sociedad civil ilustrada en la que la educación jugara un papel fundamental) ${ }^{32}$, por lo que al ser liberales, masones y promotores de la educación, muchos de estos personajes lograron alcanzar varios objetivos en una sola acción social. También hubo muchos no masones que

${ }^{29}$ Morales García, Cultura oligárquica y nueva intelectualidad, 79-80. Molina Jiménez, La estela de la pluma. Cultura impresa e intelectuales en Centroamérica durante los siglos XIX y XX (Heredia: EUNA, 2004), 115-130.

${ }^{30}$ Molina Jiménez, Demoperfectocracia. La democracia pre-formada en Costa Rica (1885-1948) (Heredia: EUNA, 2005), 31-60.

31 Acerca de la vida masónica de estos dos importantes líderes de la masonería centroamericana decimonónica, pueden consultarse: Guzmán-Stein, “Dr. José María Castro Madriz: Masón y liberal, diputado, embajador, ministro, Presidente de la República, Presidente del Congreso, Presidente de la Corte Suprema de Justicia", en La masonería española en la época de Sagasta (1825-1903), coord. Ferrer Benimeli (Zaragoza: CEHME y la Fundación Práxedes Mateo-Sagasta, 2006), Tomo II, 927-976; y Roberto Marín Guzmán, "Un masón-antijesuita en Costa Rica en el siglo XIX: el caso del doctor Lorenzo Montúfar”, en Gibraltar, Cádiz, América y la masonería. Constitucionalismo y libertad de prensa, 1812-2012, coord. José Miguel Delgado Idarreta y Antonio Morales Benítez (Gibraltar: Gobierno de Gibraltar-CEHME, Universidad de Zaragoza, 2014), Tomo II, 725-748.

${ }^{32}$ Las transformaciones que empezó a experimentar el aparato educativo costarricense a finales del siglo XIX fue un fenómeno coyuntural a nivel global de laicización y secularización de la educación. Julie A. Reuben, Making of the Modern University: Intellectual Transformation and the Marginalization of Morality (Chicago: University Chicago Press, 1996). Charles A. Hale, "Political and Social Ideas in Latin America, 1870-1930", en The Cambridge History of Latin America, ed. Leslie Bethell (Nueva York: Cambridge University Press, 1986), Tomo IV, 382-414. 
promovieron la educación secularizada, lo cual demuestra el tono de los tiempos, el cual a su vez explica muchas de las acciones sociales de quienes se asociaron a una logia masónica. Por ejemplo, el liberal Mauro Fernández Acuña -de quien se ha reproducido el mito de su pertenencia a la masonería $-{ }^{33}$, líder de la reforma de mediados de la década de 1880, que impulsó decisivamente la alfabetización popular, integró socioculturalmente al país, eliminó la educación religiosa y promovió la formación ciudadana por medio de los centros educativos $^{34}$; o el caso del no tan liberal y declarado antimasón, Jesús Jiménez Zamora (1868-1870), que llevó a cabo la reforma propuesta en 1867 por los masones, el citado Castro Madriz y Julián Volio Llorente (ambos abogados), de declarar constitucionalmente la educación primaria gratuita, obligatoria y costeada por el Estado ${ }^{35}$.

Por lo tanto, la prosopografía permite observar que no hubo un monopolio por parte de los masones o que estos fueran los actores dominantes en la educación. Sin embargo, hubo masones ostentando los puestos más altos y relevantes del aparato educativo, por lo que pudieron haber estado entre los personajes de mayor influencia durante dichos años, y si no, sobresalieron como vanguardistas en la llegada de nuevas filosofías educativas a Costa Rica. La mayoría de los masones participantes en el aparato educativo de al época, se refiere a profesores de institutos secundarios o universitarios, rectores de la Universidad de Santo Tomás y ministros de Instrucción Pública. Esto les brindó a estas personas prestigio social, lo cual encajó con sus facetas como masones, ya que la masonería costarricense del periodo se comportó como un fenómeno esencialmente de élites.

La participación de los masones desenvolviendo roles de poder en el aparato educativo costarricense o promoviendo nuevas filosofías educativas, también lo detectaron los sectores antiliberales del país. Por ejemplo, la reforma educativa de mediados de la década de 1880, en los años posteriores, la prensa católica la representó como un proyecto impulsado desde la logia masónica ${ }^{36}$. No obstante, esta representación hecha por algunos sectores de la Iglesia católica formó parte de las construcciones sociales integradas a los argumentos comunes de satanización del liberalismo en la Latinoamérica decimonónica.

\footnotetext{
${ }^{33}$ Claudio Vargas Arias, El Liberalismo, la Iglesia y el Estado en Costa Rica (San José: Editorial Guayacán, 1990), 165.

${ }^{34}$ Quesada Camacho, "Un siglo de educación costarricense 1814-1914", Cuadernos de Historia de las Instituciones de Costa Rica 23 (San José: EUCR, 2005), 28-33.

${ }_{35}^{35}$ Quesada Camacho, "Un siglo de educación costarricense", 12-20.

36 Martínez Esquivel, "Documentos y discursos católicos antimasónicos en Costa Rica (1865-1899)", REHMLAC 1, no. 1 (mayo-noviembre 2009 [citado el 5 de junio de 2015]): disponible en http://rehmlac.com/recursos/vols/v1/n1/rehmlac.vol1.n1-543rich.pdf; Martínez Esquivel, "Conspiradores políticos y sectas misteriosas: Imaginarios sociales sobre la masonería en Costa Rica (1865-1899)", Revista Estudios 22 (2009 [citado el 15 de julio de 2016]): disponible en http://revistas.ucr.ac.cr/index.php/estudios/article/view/24182/24810; y Esteban Sánchez Solano, "La identificación del desarticulador del mundo católico en Costa Rica (1880-1900)", en 300 años: masonerías y masones, 1717-2017. Tomo II: Silencios, eds. Martínez Esquivel, Pozuelo Andrés y Aragón (Ciudad de México: Palabra de Clío, 2017), 33-49.
} 
En otras palabras, hubo un grupo de masones liderando reformas educativas, ya sea ostentando los principales cargos o como vanguardistas en la llegada de nuevas filosofías educativas a Costa Rica. Entre estos masones sobresalieron los abogados Castro Madriz, Montúfar y Volio Llorente, o los hermanos Fernández Ferraz, entre otros ${ }^{37}$; pero sin ser los únicos, ya que también hubo otros personajes no masones en este proceso, como el también abogado Fernández Acuña, líder de la reforma educativa de 1886. Por consiguiente, lo que parece haber sucedido fue más bien que estos masones participaron de una red élite de personas identificadas con los ideales del liberalismo y la modernidad, que se constituyó en el poder político durante la década de 1880, logrando finalmente institucionalizar un proyecto educativo que se venía delineando desde décadas anteriores. No obstante, estos actores perdieron el poder político con la crisis electoral del año 1889.

\section{Conclusión}

No hubo una escuela masónica ni una pedagogía masónica, hubo apoyos en solitario y sobre todo junto a otros colectivos para llevar a cabo esa realidad educativa influenciada fundamentalmente en España y en países latinoamericanos como Costa Rica, en los sectores liberales, por el krausismo. La generación introductoria esta ideología en España no pasó en general por la logia, rencorosa por la expulsión que sufrió Krause de la masonería germana. Sin embargo, las siguientes generaciones de krausistas se adhirieron a la masonería y de esta manera emprendieron acciones e intentos que cumplieron con el espíritu modernizador que albergaba el Ideal de la Humanidad para la vida de Krause, obra cuyo subtítulo era "Preferentemente para masones".

No eran la masonería y los masones lo suficientemente pudientes, como se vino también difundiendo desde la antimasonería religiosa, como para crear y sostener escuelas laicas en todas las regiones de un país. No había suficiente dinero para crear y sostener esas escuelas por parte de una logia ni una obediencia porque no solo se dedicaba el dinero masónico a esa labor. Su filantropía se extendía a múltiples causas: fundar internados para huérfanos, crear bibliotecas, ayudas para hospitales o tras una catástrofe natural, becar a jóvenes investigadores universitarios, etcétera. Incluso como no podía ser de otra manera, en muchos casos se tuvo que afrontar la compra o la construcción de un templo que pudiera albergar las reuniones de las logias, empresa muy costosa.

A partir del caso de la relación entre educación escolar y masonería en Costa Rica, la prosopografía permite demostrar el desarrollo de redes más amplias enfocadas a la institucionalización de paradigmas modernos como el racionalismo y el derecho a recibir educación en el país. Del mismo modo, el grupo de masones en el país no se constituyó en un coto cerrado o exclusivo en su praxis social. Los masones participaron de la esfera

\footnotetext{
${ }^{37}$ González Flores, Evolución de la instrucción pública en Costa Rica, 293-318.
} 
pública costarricense junto a otros actores no masones, en la defensa, la promoción y el debate de ideas consideradas de vanguardia para la época, así como en el desenvolvimiento de nuevas sociabilidades y asociaciones. Los masones funcionan como un ejemplo de que ellos no desarrollaron una red singular en la modernización del país, sino que más bien, participaron de redes que sobrepasaron la masonería misma.

El proceso de llegada de la modernidad a la Costa Rica decimonónica lo promovieron, defendieron y favorecieron diversas redes de políticos e intelectuales. Estas tuvieron diversos objetivos y metas, según los intereses grupales o individuales de sus líderes, pero siempre caracterizándoles la militancia de sus miembros en el pensamiento liberal, la ilustración y la ideología del progreso. En estas redes participaron masones, a veces siendo mayoría, pero nunca los únicos, ya que el significado de la modernidad durante estos años se constituyó en el elemento clave de cohesión de estas personas y no así, la asociación a una organización como la masonería. El análisis prosopográfico comprueba el desarrollo de una masonería funcionando como una red entre muchas otras durante la modernización del país en el siglo XIX. Por ende, la masonería en su carácter de sociabilidad se consolidó como un importante exponente de la modernidad cultural, en el sentido de que colaboró en la promoción de ideas consideradas novedosas y en la construcción de redes de sociabilidad artística, filosófica, científica o educativa, o en otras palabras, ayudando en el desarrollo de la institucionalidad cultural o, como dirían en la época, de la civilización.

Por último, se señala que las relaciones económicas, intelectuales y de parentesco en la secularización de la educación, condicionaron positivamente la asociación de personas a una masonería que se representó como defensora de estos ideales. Durante esta época, el tener una vida pública diversa y cosmopolita fue algo que ayudó a los actores sociales en su integración a la masonería costarricense de estos años.

\section{Fuentes primarias}

Archivo de la Gran Logia de Costa Rica

Ficheros de expedientes antiguos (1865-1899).

Estatutos civiles de la Masonería de Centro América (San José, 1884).

Registro de firmas de la Respetable Logia Unión Fraternal 19 (1883-1887).

Registro de firmas de la Respetable Logia Regeneración 6 (1888-1899).

Archivo Nacional de Costa Rica

Series de Gobernación, Libro 1234, Folio 77. 


\section{Bibliografía}

Álvarez Lázaro, Pedro. Páginas de historia masónica. Madrid: IDEA, 2006.

Asín Vergara, Rafael. "Relaciones e influencias entre la masonería y la Institución Libre de Enseñanza”. En La masonería en la España del siglo XX. Coordinado por José Antonio Ferrer Benimeli. Zaragoza: CEHME, 1996.

Cruz Orozco, José Ignacio. Masonería y Educación en la II República española. Alicante: Instituto de Cultura "Juan Gil-Albert", 1993.

Ferrer Benimeli, José Antonio. Índices de actas de los Symposia Internacionales de Historia de la Masonería Española. Zaragoza: CEHME, 2009.

Ferrer Benimeli, José Antonio. "La escuela laica. Lugar de enfrentamiento entre la masonería y la Iglesia en España (1868-1930)”. En École et Église en Espagne et en Amérique Latine -Aspects idéologiques et institutionnels. Editado por JeanRené Aymes, Eve-Marie Fell y Jean-Louis Guerena. Tours : Université de Tours, 1988.

Ferrer Benimeli, José Antonio. "Preocupación de la masonería de Tánger por la educación y la paz en Marruecos (1905-1920)”. En Cuadernos de historia contemporánea 14 (1992): 75-89.

Gómez Molleda, María Dolores. "Educación, masonería y Segunda República. Algunos aspectos críticos". En Historia de la Educación 27 (2008): 131-152.

González Flores, Luis Felipe. Historia de la influencia extranjera en el desenvolvimiento educacional y científico de Costa Rica. San José: ECR, 1976.

González Flores, Luis Felipe. Evolución de la instrucción pública en Costa Rica. San José: ECR, 1978.

González Villalobos, Paulino. La Universidad de Santo Tomás. San José: EUCR, 1989.

Guerra, François-Xavier. Modernidad e independencias. Ensayos sobre las revoluciones hispánicas. Madrid: Editorial MAPFRE, 1992.

Guzmán-Stein, Miguel. "Masones españoles en Costa Rica: el Krausismo y la Institución Libre de Enseñanza en la formación y desarrollo de la Democracia Liberal Costarricense". En Masonería Española y América. Coordinado por José Antonio Ferrer Benimeli. Zaragoza: CEHME, 1993.

Guzmán-Stein, Miguel. "Masones y liberales, españoles y cubanos: Intervención y aporte al desarrollo social, político y cultural de Costa Rica en el siglo XIX". En La Masonería Española entre Europa y América. Coordinado por José Antonio Ferrer Benimeli. Zaragoza: CEHME, 1995.

Guzmán-Stein, Miguel. "Costa Rica, España y Cuba: Antecedentes, desarrollo e impacto del movimiento de independencia en la sociedad costarricense finisecular y la masonería”. En La Masonería Española y la crisis colonial del 98. Coordinado por José Antonio Ferrer Benimeli. Zaragoza: CEHME, 1999. 
Guzmán-Stein, Miguel. "Dr. José María Castro Madriz: Masón y liberal, diputado, embajador, ministro, Presidente de la República, Presidente del Congreso, Presidente de la Corte Suprema de Justicia”. En La masonería española en la época de Sagasta (1825-1903). Coordinado por José Antonio Ferrer Benimeli. Zaragoza: CEHME y la Fundación Práxedes Mateo-Sagasta, 2006.

Hale, Charles A. "Political and Social Ideas in Latin America, 1870-1930". En The Cambridge History of Latin America. ed. Leslie Bethell. Nueva York: Cambridge University Press, 1986.

Ledesma Reyes, Manuel. "Krausismo y educación en Costa Rica: La influencia de los educadores canarios: Valerio y Juan Fernández Ferraz". Tesis de Doctorado en Filosofía, Universidad de La Laguna, 1994.

Marín Guzmán, Roberto. "Un masón-antijesuita en Costa Rica en el siglo XIX: el caso del doctor Lorenzo Montúfar". En Gibraltar, Cádiz, América y la masonería. Constitucionalismo y libertad de prensa, 1812-2012. Coordinado por José Miguel Delgado Idarreta y Antonio Morales Benítez. Gibraltar: Gobierno de GibraltarCEHME, Universidad de Zaragoza, 2014.

Martínez Esquivel, Ricardo. "Documentos y discursos católicos antimasónicos en Costa Rica (1865-1899)". En REHMLAC 1, no. 1 (mayo-noviembre 2009 [citado el 10 de octubre de 2010]): disponible en http://revistas.ucr.ac.cr/index.php/REHMLAC/article/view/6860/6547

Martínez Esquivel, Ricardo. "Conspiradores políticos y sectas misteriosas: Imaginarios sociales sobre la masonería en Costa Rica (1865-1899)". En Revista Estudios 22 (2009 [citado el 10 de octubre de 2014]): disponible en http://revistas.ucr.ac.cr/index.php/estudios/article/view/24182/24810

Martínez Esquivel, Ricardo. Masones y masonería en la Costa Rica de los albores de la Modernidad (1865-1899). San José: EUCR, 2017.

Molina Jiménez, Iván y Steven Palmer, Héroes al Gusto y Libros de Moda. Sociedad y cambio cultural en Costa Rica (1750-1900) (San José: Editorial Porvenir, Plumsock Mesoamerican Studies, 1992).

Molina Jiménez, Iván. La estela de la pluma. Cultura impresa e intelectuales en Centroamérica durante los siglos XIX y XX. Heredia: EUNA, 2004.

Molina Jiménez, Iván. Demoperfectocracia. La democracia pre-formada en Costa Rica (1885-1948). Heredia: EUNA, 2005.

Molina Jiménez, Iván. "Educación y sociedad en Costa Rica: de 1821 al presente (una historia no autorizada)". En Diálogos Revista Electrónica de Historia 8, no. 2 (agosto 2007-febrero 2008 [citado el 15 de septiembre de 2015]): disponible en http://revistas.ucr.ac.cr/index.php/dialogos/article/view/18349/18539

Mollés, Dévrig. "Transferencias y luchas culturales transatlánticas desde Argentina (18601910)”. En 300 años: masonerías y masones, 1717-2017. Tomo I: Migraciones. 
Editado por Ricardo Martínez Esquivel, Yván Pozuelo Andrés y Rogelio Aragón. Ciudad de México: Palabra de Clío, 2017.

Morales García, Gerardo. Cultura oligárquica y nueva intelectualidad en Costa Rica: 1880-1914. Heredia: EUNA, 1995.

Muñoz García, Ileana. Educación y régimen municipal en Costa Rica 1821-1882. San José: EUCR, 2002.

Obregón Loría, Rafael y George Bowden. La Masonería en Costa Rica Tomo II. San José: Trejos Hermanos, 1938.

Palacios Robles, María de los Ángeles. "La formación del ciudadano costarricense de 18211886". En Cuadernos para la Ciudadanía 3. San José: EUCR, 2005.

Pozuelo Andrés, Yván. La masonería en Asturias (1931-1939). Oviedo: Universidad de Oviedo, 2012.

Quesada Camacho, Juan Rafael. "Un siglo de educación costarricense 1814-1914". En Cuadernos de Historia de las Instituciones de Costa Rica 23. San José: EUCR, 2005.

Quesada Camacho, Juan Rafael. Educación y ciudadanía en Costa Rica de 1810 a 1821: del crepúsculo colonial al umbral de la modernidad política. San José: EUCR, 2007.

Reuben, Julie A. Making of the Modern University: Intellectual Transformation and the Marginalization of Morality. Chicago: University Chicago Press, 1996.

Rich, Paul John. Elixir of Empire: The English Public Schools, Ritualism, Freemasonry, and Imperialism. Londres: Regency Press Ltd., 1989.

Sánchez Solano, Esteban. "La identificación del desarticulador del mundo católico en Costa Rica (1880-1900)". En 300 años: masonerías y masones, 1717-2017. Tomo II: Silencios. Editado por Ricardo Martínez Esquivel, Yván Pozuelo Andrés y Rogelio Aragón. Ciudad de México: Palabra de Clío, 2017.

Ureña, Enrique M. "Masonería y pensamiento: Krause”, en La masonería en la España del siglo XIX. Coordinado por José Antonio Ferrer Benimeli. Madrid: Junta de Castilla y León, Consejería de Educación y Cultura, 1987.

Vargas Arias, Claudio. El Liberalismo, la Iglesia y el Estado en Costa Rica. San José: Editorial Guayacán, 1990. 